\title{
Ce:YAG Transparent Ceramics Enabling High Luminous Efficacy for High-power LEDs/LDs
}

\author{
DU Aochen ${ }^{1,2}$, DU Qiyuan ${ }^{3}$, LIU Xin ${ }^{2,4}$, YANG Yimin $^{1,2}$, XIA Chenyang $^{1}$, ZOU Jun ${ }^{3}$, LI Jiang ${ }^{2,4}$ \\ (1. School of Materials Science and Engineering, Jilin Jianzhu University, Changchun 130118, China; 2. Key Laboratory of \\ Transparent Opto-functional Inorganic Materials, Shanghai Institute of Ceramics, Chinese Academy of Sciences, Shanghai, \\ 201899, China; 3. School of Science, Shanghai Institute of Technology, Shanghai, 201418, China; 4. Center of Materials \\ Science and Optoelectronics Engineering, University of Chinese Academy of Sciences, Beijing 100049, China)
}

\begin{abstract}
Ce:YAG transparent ceramics could be combined with blue LEDs/LDs, for applications of high power white LEDs/LDs. In this study, it is found that by adjusting the thickness of Ce:YAG transparent ceramics and the doping concentration of $\mathrm{Ce}^{3+}$, the emission spectra and color coordinates of the assembled devices can be adjusted from the cold white region to the warm white region. $\left(\mathrm{Ce}_{x} \mathrm{Y}_{1-x}\right)_{3} \mathrm{Al}_{5} \mathrm{O}_{12}(x=0.0005,0.0010,0.0030,0.0050,0.0070$ and 0.0100) transparent ceramics was fabricated by a solid state reaction method, with the high pure $(\geqslant 99.99 \%)$ commercial powders $\alpha-\mathrm{Al}_{2} \mathrm{O}_{3}, \mathrm{Y}_{2} \mathrm{O}_{3}$ and $\mathrm{CeO}_{2}$ using as raw materials. The ceramic green bodies were sintered in $1750{ }^{\circ} \mathrm{C}$ for $20 \mathrm{~h}$ under vacuum of $5.0 \times 10^{-5} \mathrm{~Pa}$, and the ceramics were annealed at $1450{ }^{\circ} \mathrm{C}$ for $10 \mathrm{~h}$ in the muffle furnace. The in-line transmittance of double polished Ce:YAG ceramics is higher than $79 \%$ at $800 \mathrm{~nm}(0.2,0.4$, $1.0 \mathrm{~mm}$ in thickness, respectively). The thermal conductivity of Ce:YAG transparent ceramics decreases with the increase of measuring temperature and doping concentration. Thermal distribution of ceramics and LEDs with different thicknesses was simulated by the finite element method, and the thermal distributions of three packaging modes were compared. White light with chromaticity coordinates of $(0.3319,0.3827)$ and $(0.3298,0.3272)$ and luminous efficiency of 122.4 and $201.5 \mathrm{~lm} / \mathrm{W}$ were prepared by combining transparent ceramics with LEDs/LDs. We combined Ce:YAG transparent ceramics and blue LEDs chips to produce 10 and $50 \mathrm{~W}$ mature lamps, which can be used for commercial purposes. Therefore, the Ce:YAG transparent ceramics is a highly promising color conversion material for high power lighting and displaying applications in the future.
\end{abstract}

Key words: LEDs/LDs illumination; photoluminescence; Ce:YAG; ceramic phosphor

With the development of high-power white light-emitting diode (LEDs) and laser diode (LDs), phosphors in glass $(\mathrm{PiG})^{[1]}$, single crystals $(\mathrm{SC})^{[2]}$ and transparent ceramics $(\mathrm{TC})^{[3-4]}$ were proposed to overcome the influence of high temperature on the luminous efficiency (LE) and lifetime of phosphors in resin or silicone. White lightemitting diode (WLEDs) composed of blue LED chip and yellow emitting $\mathrm{Ce}: \mathrm{Y}_{3} \mathrm{Al}_{5} \mathrm{O}_{12}$ (Ce:YAG) phosphor is widely used in solid-state lighting (SSL) ${ }^{[5-7]}$. As a new generation of color conversion materials, $\mathrm{Ce}^{3+}$ ion doped yttrium aluminum garnet transparent ceramics are favored by researchers for their high thermal conductivity (about $\left.8 \mathrm{~W} \cdot \mathrm{m}^{-1} \cdot \mathrm{K}^{-1}\right)^{[8]}$ and excellent mechanical properties, so they are developing rapidly. But the "efficiency droop" of blue LEDs limits the development in the field of highpower lighting ${ }^{[9-10]}$. Laser diodes have the advantages of smaller size, high brightness, fast switching speed and especially under the ultra-high driving power density. In the period of high-power white light illumination, the performance of white light LDs is better than that of white LEDs in all aspects, so it is an ideal substitute ${ }^{[11]}$. Therefore, the design idea of white LDs through blue laser diode combined with Ce:YAG transparent ceramics has been proposed in automobile illumination, displays,

Received date: 2020-12-18; Revised date: 2021-01-24; Published online: 2021-03-12

Foundation item: National Key R\&D Program of China (2017YFB0310500); Key Research Project of the Frontier Science of the Chinese Academy of Sciences (QYZDB-SSW-JSC022)

Biography: DU Aochen (1995-), male, Master candidate. E-mail: duaochen@foxmail.com

杜傲宸(1995-), 男, 硕士研究生. E-mail: duaochen@foxmail.com

Corresponding author: LI Jiang, professor. E-mail: lijiang@mail.sic.ac.cn

李 江, 研究员. E-mail: lijiang@mail.sic.ac.cn 
projectors, headlights, and other special lighting fields to get ultrahigh brightness by consuming lower energy ${ }^{[12]}$. The color conversion materials for LEDs/LDs lighting need to meet certain requirements. The following three aspects are essential: high absorption rate of blue light, high luminous efficiency and good optical performance. At present, Ce:YAG phosphor is considered to be the most suitable material ${ }^{[13]}$. Compared with $\mathrm{SC}$ and $\mathrm{PiG}$, TC have become the most promising type because of its lower cost and higher thermal conductivity. Thus, for LEDs lighting Ce:YAG usually have a better performance in TCs $(\approx 120 \mathrm{~lm} / \mathrm{W})^{[14]}$ than that in PiGs $(\approx 80 \mathrm{~lm} / \mathrm{W})^{[15-16]}$.

At present, in order to optimize the luminous performance and heat transfer efficiency of Ce:YAG ceramics, almost all process parameters, such as thickness, doping concentration and radius, have been studied in detail ${ }^{[17-18]}$. By simply changing the thickness of cerium yttrium aluminum garnet ceramics $(0.2-1.5 \mathrm{~mm})$, the emission color of the assembled LEDs can be adjusted from cold white $(0.29,0.31)$ to warm white $(0.39,0.49)^{[19]}$. In addition, Yao, et $a l^{[17]}$ used ANSYS software to effectively analyze the temperature variation, heat distribution and heat flux of Ce:YAG transparent ceramics in different packaging modes of LEDs. Therefore, from the above research results, a simple conclusion can be drawn that Ce:YAG transparent ceramics have a bright application prospect in lighting industry. Preparing transparent ceramics with high optical quality and selecting suitable ceramic thickness combined with blue LEDs/LDs with different powers can be applied to many scenes. In the research process, due to the limitation of the shape of the purchased LED chip and the ceramic processing technology, the three LED packaging modes commonly used in the laboratory were simulated by the finite element method, and the reasonable ceramic surface temperature was obtained. And a conclusion is drawn that the thicker the ceramic is, the lower the surface temperature will be, which is of great significance for the design of white LEDs, and many influencing factors can be considered more comprehensively.

In this study, we fabricated an outstanding phosphorconverter with high thermal conductivity (Ce:YAG transparent ceramics). The transparent ceramics with different concentrations and thickness were systematically investigated by in-line transmittance, luminescence intensity and device testing such as luminous efficiency (LE), Commission Internationale de 1'Eclairage (CIE), Color Rendering Index (CRI) and electroluminescence (EL), by combining the ceramics with blue LEDs/LDs. The temperature distributional simulation of Ce:YAG transparent ceramics were effectively analyzed by COMSOL Multiphysics finite element software. The work reveals the law of combining LEDs/LDs with different $\mathrm{Ce}^{3+}$ concentrations and ceramic thickness, and makes a series of lamps by combining transparent ceramics with blue LEDs, so as to guide and promote the development of combining highpower LEDs/LDs with Ce:YAG transparent ceramics.

\section{Experimental}

\subsection{Synthesis}

Ce:YAG ceramics were synthesized via solid-state sintering. Firstly, the raw materials for the ceramics were high purity $\alpha$-alumina $\left(\alpha-\mathrm{Al}_{2} \mathrm{O}_{3}, 99.99 \%\right.$ purity, Yangzhou Zhongtianli Materchem Co., Ltd, China), yttrium oxide $\left(\mathrm{Y}_{2} \mathrm{O}_{3}, 99.99 \%\right.$ purity, Shanghai Sheeny Metal Co., Ltd, China) and $\mathrm{CeO}_{2}$ (99.99\% purity, Alfa Aesar Chemical Co., Ltd, China) powders. The average particle sizes of $\mathrm{Y}_{2} \mathrm{O}_{3}$ and $\alpha-\mathrm{Al}_{2} \mathrm{O}_{3}$ powders are about 40 and $300 \mathrm{~nm}$, respectively. The starting materials were weighed accurately in the ratio of $\left(\mathrm{Ce}_{x} \mathrm{Y}_{1-x}\right)_{3} \mathrm{Al}_{5} \mathrm{O}_{12}(x=0.0005,0.0010,0.0030$, $0.0050,0.0070$ and 0.0100 ), and $0.8 \mathrm{wt} \%$ tetraethyl orthosilicate (TEOS, $>99.999 \%$, Alfa Aesar, Tianjin, China) and $0.08 \mathrm{wt} \% \mathrm{MgO}$ (99.998\%, Alfa Aesar, Tianjin, China) were added as the sintering additives. The material used for the container and milling balls is alumina. Then the mixed powders were milled on a planetary ball mill for $12 \mathrm{~h}$ with $10 \mathrm{~mm}$ diameter balls in ethanol. The disc and bottle rotation speeds were 130 and $260 \mathrm{r} / \mathrm{min}$, respectively. After drying for $2 \mathrm{~h}$ in an oven at $70{ }^{\circ} \mathrm{C}$, the mixture was sieved through a 200 -mesh $(74 \mu \mathrm{m})$ screen three times. The obtained powders were calcined at $600{ }^{\circ} \mathrm{C}$ for $4 \mathrm{~h}$ in a muffle furnace to remove the organic residuals. Using molds with a circular shape $(\Phi=18 \mathrm{~mm})$, the ceramic plates were loaded and compacted under $20 \mathrm{MPa}$, and then the green bodies were achieved after cold isostatic pressing at $250 \mathrm{MPa}$. Next, the green bodies were sintered at $1750{ }^{\circ} \mathrm{C}$ for $20 \mathrm{~h}$ under vacuum of $5.0 \times 10^{-5} \mathrm{~Pa}$. The as-sintered samples were annealed at $1450{ }^{\circ} \mathrm{C}$ for $10 \mathrm{~h}$ in a muffle furnace to eliminate the oxygen vacancies, and then they were machined and doublesurface polished to different thickness of $0.2,0.4$ and $1.0 \mathrm{~mm}$ for further measurement and device packing. The flowchart of whole preparation process is shown in Fig. 1.

\subsection{Characterizations}

For the optical measurements, the in-line transmittance of the mirror-polished YAG ceramics over the wavelength range from 200 to $800 \mathrm{~nm}$ were tested by a UV-Vis-NIR spectrophotometer (Cary 5000, Varian Medical System Inc. Palo Alto, USA). The X-ray powder diffraction (XRD) test used Huber G670 Guinier imaging diffractometer $\left(\mathrm{CuK} \alpha_{1}(\lambda=0.154056 \mathrm{~nm}), 40 \mathrm{kV} / 30 \mathrm{~mA}\right.$, germanium monochromator) of Germany, scanning diffraction pattern 


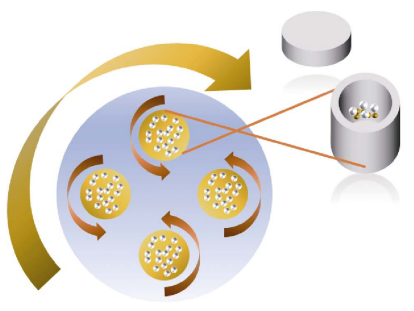

Planetary ball milling (top view)

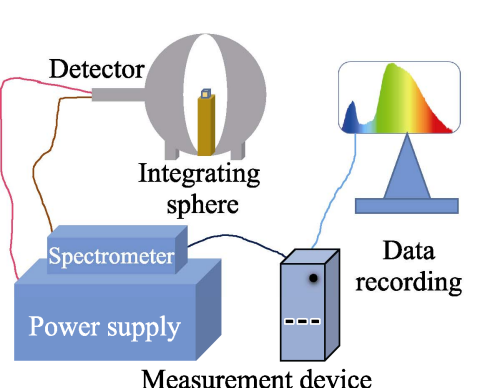

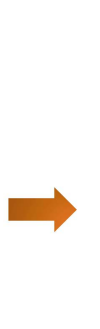

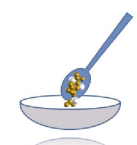

Grinding

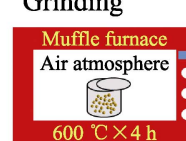

Sintering Dry pressing CIP Forming process
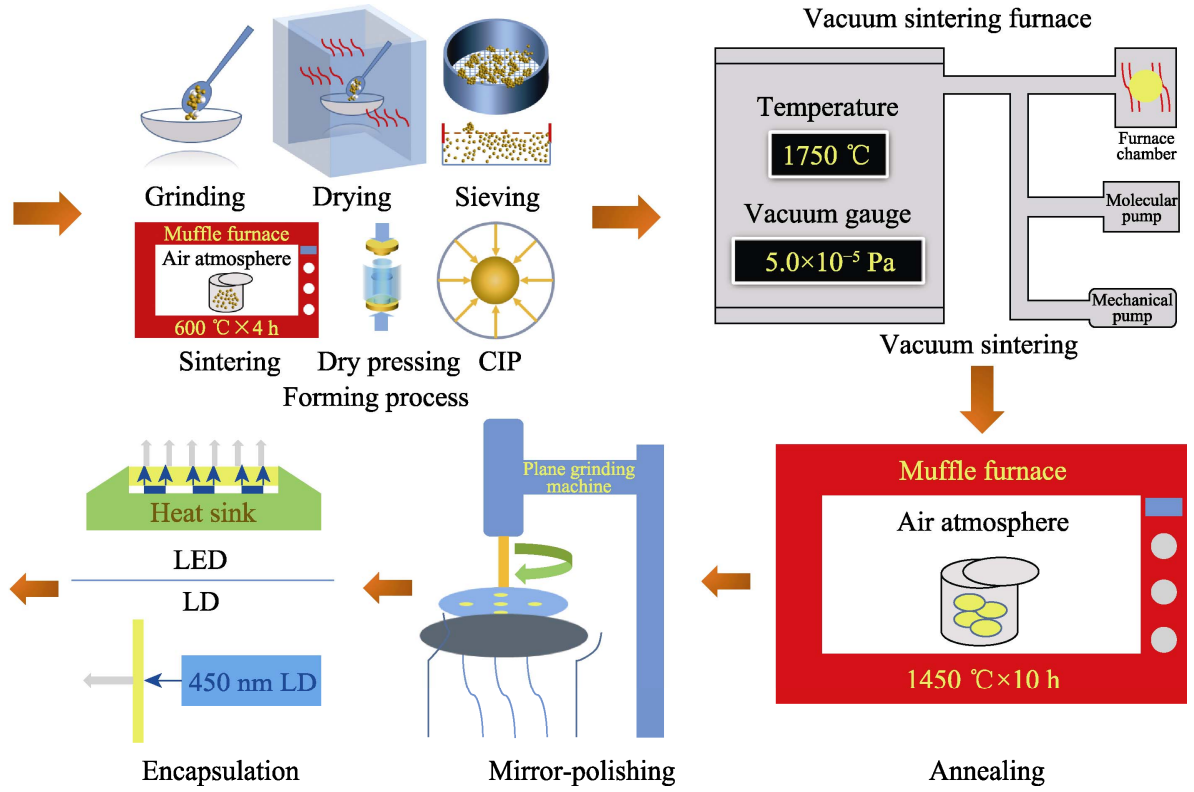

Annealing

Fig. 1 Flowchart for the preparation process of Ce:YAG transparent ceramics

in the range of $25^{\circ}-75^{\circ}\left(\right.$ step state $0.02^{\circ}$ ). A fluorescence spectrophotometer (Hitachi, F-4600, Japan) was used to test the temperature-dependent photoluminescence (PL) in the temperature ranges from RT to $250{ }^{\circ} \mathrm{C}$ with the heating rate of $50{ }^{\circ} \mathrm{C} / \mathrm{min}$, with Xe lamp as an excitation source. The specific heat was recorded by high temperature specific heat meter (MHTC96, Setaram, France) and the heat conductivity coefficient was recorded by a homemade laser pulse apparatus. The bulk density of the prepared ceramics was measured by the Archimedes principles. Combining the ceramics with blue LEDs, the optical properties of the ceramic-based LEDs were studied. The luminous efficiency, Commission Internationale de L'Eclairage (CIE) color coordinate and electroluminescent properties under different input currents were detected using a high accuracy array spectroradiometer (HASS-2000, Hangzhou, China), with programmable LEDs test power supply (LEDs 300E, Hangzhou, China). For LDs application, transmission mode was firstly used, wherein the ceramics were fixed onto a heat sink and excited using a fiber-coupling blue LDs.

\section{Results and discussion}

\subsection{Crystal structure}

Fig. 2(c) exhibits that YAG belongs to a cubic crystal system with a space group of $\mathrm{O}_{\mathrm{h}}{ }^{10}-\mathrm{Ia}_{3} \mathrm{~d}^{[20]}$. There are one $\mathrm{Y}$ site coordinated by eight $\mathrm{O}$ atoms and two $\mathrm{Al}$ sites coordinated by six or four $\mathrm{O}$ atoms. The $\mathrm{Y}$ site is linked to the neighboring two $\mathrm{AlO}_{4}$ tetrahedra by edge-sharing and vertex-sharing and four $\mathrm{AlO}_{6}$ octahedra by sharing a common edge. The ionic radius of $\mathrm{Ce}^{3+}(r=0.1143 \mathrm{~nm}$, $\mathrm{CN}=8)$ is close to that of $\mathrm{Y}^{3+}(r=0.1019 \mathrm{~nm}, \mathrm{CN}=8)^{[21]}$,
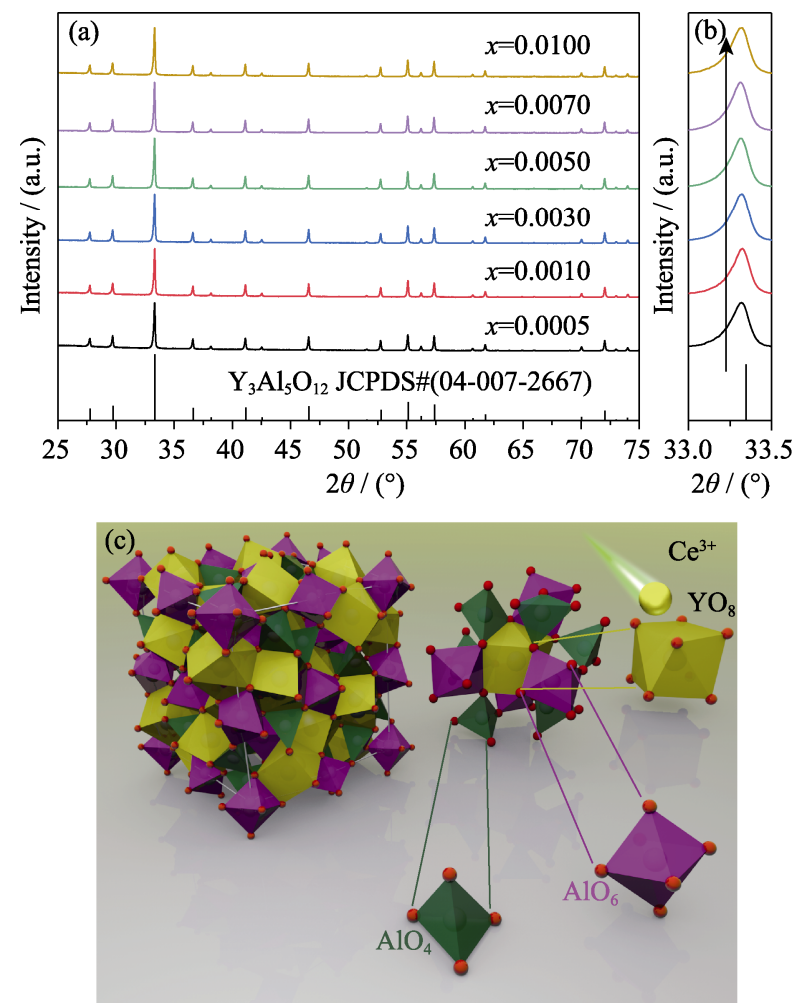

Fig. 2 XRD patterns (a) of $\left(\mathrm{Ce}_{x} \mathrm{Y}_{1-x}\right)_{3} \mathrm{Al}_{5} \mathrm{O}_{12}$ transparent ceramics smashed into powder, expanded view (b) of $2 \theta$ diffraction peaks between $33.0^{\circ}$ and $32.5^{\circ}$, and illustration of Ce:YAG crystalline structure and the coordinated environments (c) of $\mathrm{YO}_{8}$ dodecahedron, $\mathrm{AlO}_{4}$ tetrahedra, and $\mathrm{AlO}_{6}$ octahedra based on JCPDS \#04-007-2667

and thus it is believed that $\mathrm{Ce}^{3+}$ prefers to occupy the $\mathrm{Y}^{3+}$ site.

XRD patterns of $\left(\mathrm{Ce}_{x} \mathrm{Y}_{1-x}\right)_{3} \mathrm{Al}_{5} \mathrm{O}_{12}(x=0.0005,0.0010$, $0.0030,0.0050,0.0070$ and 0.0100 ) are presented in Fig. 2(a), and all samples exhibit the single garnet phase indexed to the standard YAG, JCPDS\#04-007-2667. 
Fig. 2(b) shows the diffraction peaks slightly shift to lower angles upon increasing the $\mathrm{Ce}^{3+}$ concentration, indicating that the unit cell expansion occurs due to the replacement of $\mathrm{Y}^{3+}$ by the larger $\mathrm{Ce}^{3+}$.

Fig. 3 shows the surface morphologies of Ce:YAG ceramics with different doping concentrations. All ceramic samples illustrate fully dense, pore-free microstructures without any secondary phase. For $\left(\mathrm{Ce}_{x} \mathrm{Y}_{1-x}\right)_{3} \mathrm{Al}_{5} \mathrm{O}_{12}$ ceramics with the doping concentrations of $x=0.0005,0.0010$, $0.0030,0.0050,0.0070$ and 0.0100 , the average grain sizes are $21.8,16.4,8.6,8.1,6.6$ and $5.8 \mu \mathrm{m}$, which is consistent with previous studies ${ }^{[18]}$. The decrease of the grain size is probably related to the increase of $\mathrm{Ce}^{3+}$ doping concentration. The radii of $\mathrm{Ce}^{3+}$ and $\mathrm{Y}^{3+}$ ions are different, which inhibits the grain growth.

\subsection{Optical transmittance}

The scattering performance of TCs influences its emission intensity, which is significant to the luminescence performance of the white LEDs/LDs. In Fig. 4 and Fig. 5, the appearance and optical transmittance properties of $\left(\mathrm{Ce}_{x} \mathrm{Y}_{1-x}\right)_{3} \mathrm{Al}_{5} \mathrm{O}_{12} \quad(x=0.0005,0.0010,0.0030,0.0050$, 0.0070 and 0.0100 , thickness $d=0.2 \mathrm{~mm}, 0.4 \mathrm{~mm}$ and
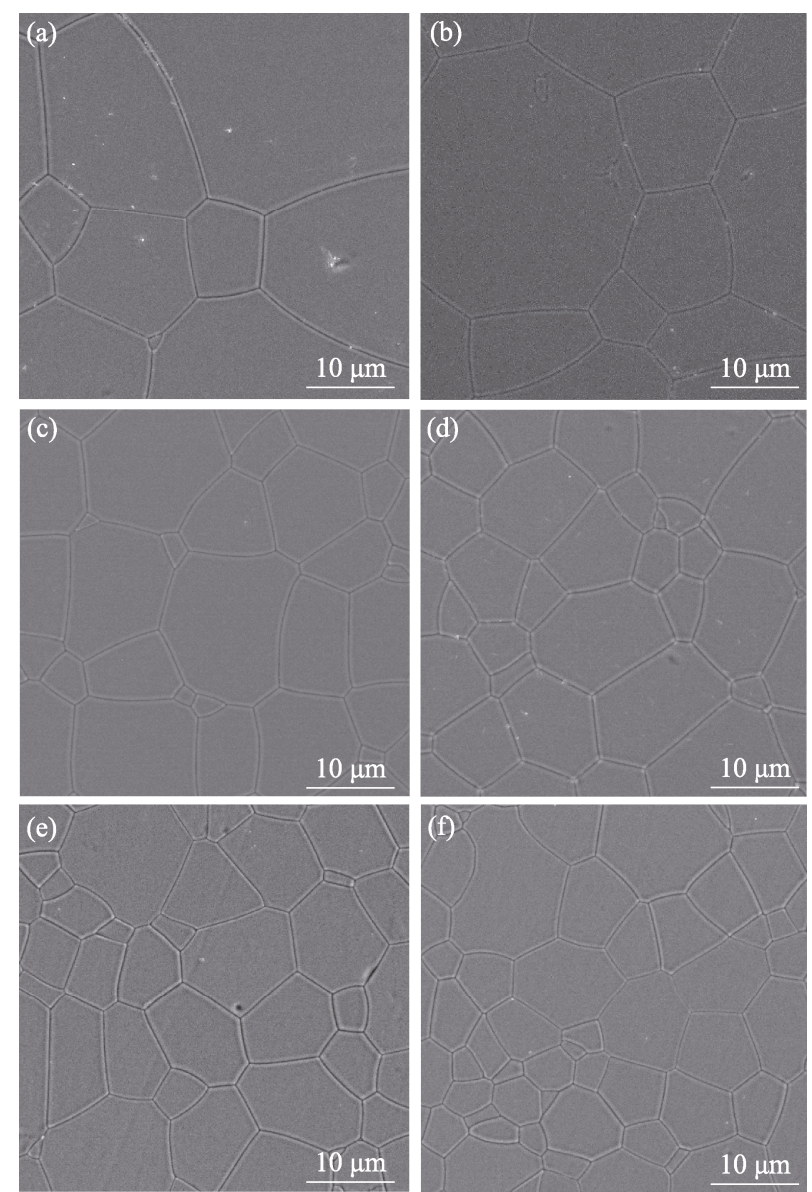

Fig. 3 FESEM images of the thermally etched surfaces of $\left(\mathrm{Ce}_{x} \mathrm{Y}_{1-x}\right)_{3} \mathrm{Al}_{5} \mathrm{O}_{12}$ ceramics with different doping concentrations (a) $x=0.0005$; (b) $x=0.0010$; (c) $x=0.0030$; (d) $x=0.0050$; (e) $x=0.0070$; (f) $x=0.0100$
$0.05 \mathrm{at} \% \mathrm{Ce} \quad 0.10 \mathrm{at} \% \mathrm{Ce} \quad 0.30 \mathrm{at} \% \mathrm{Ce} \quad 0.50 \mathrm{at} \% \mathrm{Ce} \quad 0.70 \mathrm{at} \% \mathrm{Ce} \quad 1.00 \mathrm{at} . \% \mathrm{Ce}$

E $\mathrm{Ce}: \mathrm{YAG}$ Ce:YAG Ce:YAG Ce:YAG Ce:YAG Ce:YAG

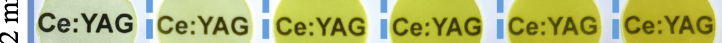

กั

Ce:YAG ICe:YAG ICe:YAG Ce:YAG Ce:YAG ICe:YAG

E Ce:YAG Ce:YÄ |Ce:YAG | Ce:YAG Ce:YAG |Ce:YAG

I Ce:YAG ICe:YAG ICe:YAG ICe:YAG ICe:YAG ICe:YAG

ナ Ce:YAG Ce:YAG Ce:YAG Ce:YAG Ce:YAG Ce:YAG

Ce:YAG Ce:YAG I Ce:YAG I Ce:YAG I Ce:YAG I Ce:YAG

Ce:YAG Ce:YAG Ce:YAG Ce:YAG Ce:YAG Ce:YAG

- Ce:YA.G |Ce:YA.G | Ce:YAG | Ce:YAG | Ce:YAG | Ce:YAG

Ce:YAG Ce:YAG Ce:YAG Ce:YAG Ce:YAG Ce:YAG

Ce:YAG Ce:YAG Ce:YAG Ce:YAG Ce:YAG $\mathrm{Ce}$ :YAG

Ce:Yag I Ce:Yag I Ce:Yag I Ce:Yag Ce:Yag Co:Yag

| $\begin{array}{lllllllllll}1 \mathrm{~cm} & 2 & 3 & 4 & 5 & 6 & 7 & 8 & 9 & 10 & 11\end{array}$

Fig. 4 Photographs of all $\left(\mathrm{Ce}_{x} \mathrm{Y}_{1-x}\right)_{3} \mathrm{Al}_{5} \mathrm{O}_{12}$ ceramics with orthogonally designed parameters under sunlight. All conditions (thickness and concentration) were independent and resulted in the great difference in color from light yellow to deep yellow

$(x=0.0005,0.0010,0.0030,0.0050,0.0070$ and $0.0100, d=0.2,0.4$ and $1.0 \mathrm{~mm})$

$1.0 \mathrm{~mm}$ ) were all above $79 \%$ at the wavelength of $800 \mathrm{~nm}$, indicating their excellent optical quality ${ }^{[22]}$. Fig. 4 shows that with the increase of $\mathrm{Ce}^{3+}$ ion concentration, the color of the polished ceramics changes from light yellow to dark yellow. At the same time, the intensities of the absorption peaks at 340 and $460 \mathrm{~nm}$ are directly proportional to the concentration of $\mathrm{Ce}^{3+}$. These two absorption peaks are attributed to $4 \mathrm{f} \rightarrow 5 \mathrm{~d}_{2}$ and $4 \mathrm{f} \rightarrow 5 \mathrm{~d}_{1}$ transitions of $\mathrm{Ce}^{3+[23]}$, which means that their combination with blue LEDs and LDs have high feasibility. The absorption band at 200$270 \mathrm{~nm}$ is probably caused by the $\mathrm{Ce}^{4+} \rightarrow \mathrm{O}^{2-}$ charge transfer through the reaction of $\mathrm{Ce}^{4+}+\mathrm{O}^{2-} \rightarrow \mathrm{Ce}^{3+}+\mathrm{O}^{-[24-25]}$. Comparing the samples before and after annealing, it is found that the UV absorption edge of air annealed samples moves to $256 \mathrm{~nm}$, which is due to the absorption of $\mathrm{Fe}^{3+}$ charge transfer band ${ }^{[26-28]}$. Generally, the $\mathrm{CeO}_{2}$ raw material could not only act as dopants, but also served as sintering additives, which affected the densification behavior of ceramics during sintering, resulting in transmission difference between samples. All above results suggest that the ceramic phosphors prepared by vacuum sintering exhibited a high optical quality, and they may be good candidates as optical conversion materials for solid-state lighting.

\subsection{Photoluminescent properties}

The fabricated ceramics show typical luminescence of $\mathrm{Ce}^{3+}$, as displayed in Fig. 6(a). It could be seen that the $5 \mathrm{~d}_{1} \rightarrow 4 \mathrm{f}$ transition of $\mathrm{Ce}^{3+}$ emission provided an asymmetric broad band characteristic, which was consisted with doublet sub-emissions from $5 \mathrm{~d}_{1} \rightarrow 4 \mathrm{f}_{5 / 2}$ and $5 \mathrm{~d}_{1} \rightarrow 4 \mathrm{f}_{7 / 2}$ transitions ${ }^{[29]}$, because the ground state of $\mathrm{Ce}^{3+}$ includes $4 \mathrm{f}_{5 / 2}$ and $4 \mathrm{f}_{7 / 2}$ sublevels after taking the spin-orbit interaction 

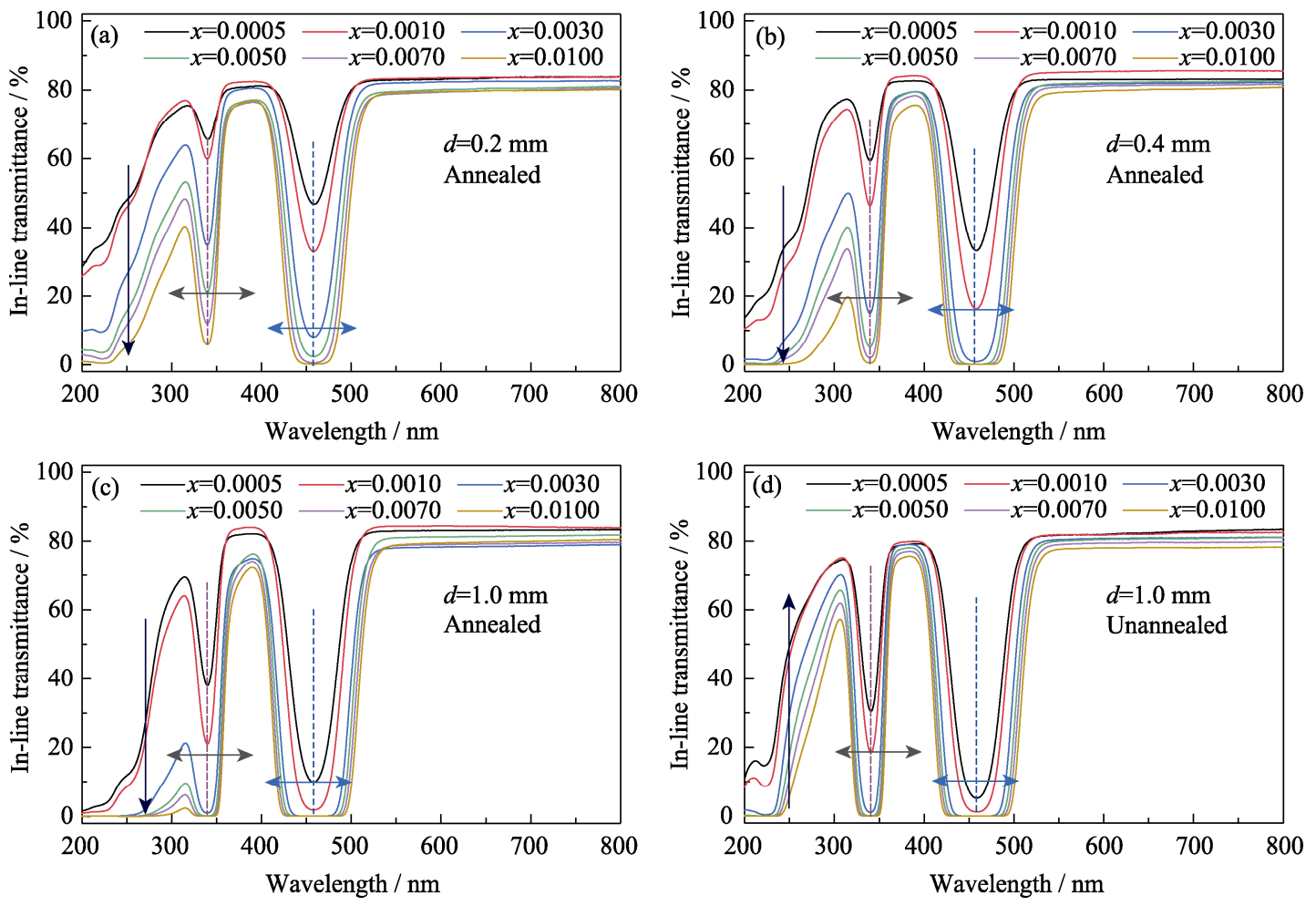

Fig. 5 In-line transmittance curves for annealed and unannealed $\left(\mathrm{Ce}_{x} \mathrm{Y}_{1-x}\right)_{3} \mathrm{Al}_{5} \mathrm{O}_{12}$ ceramics $(x=0.0005,0.0010,0.0030,0.0050,0.0070$ and $0.0100, d=0.2,0.4$ and $1.0 \mathrm{~mm})$
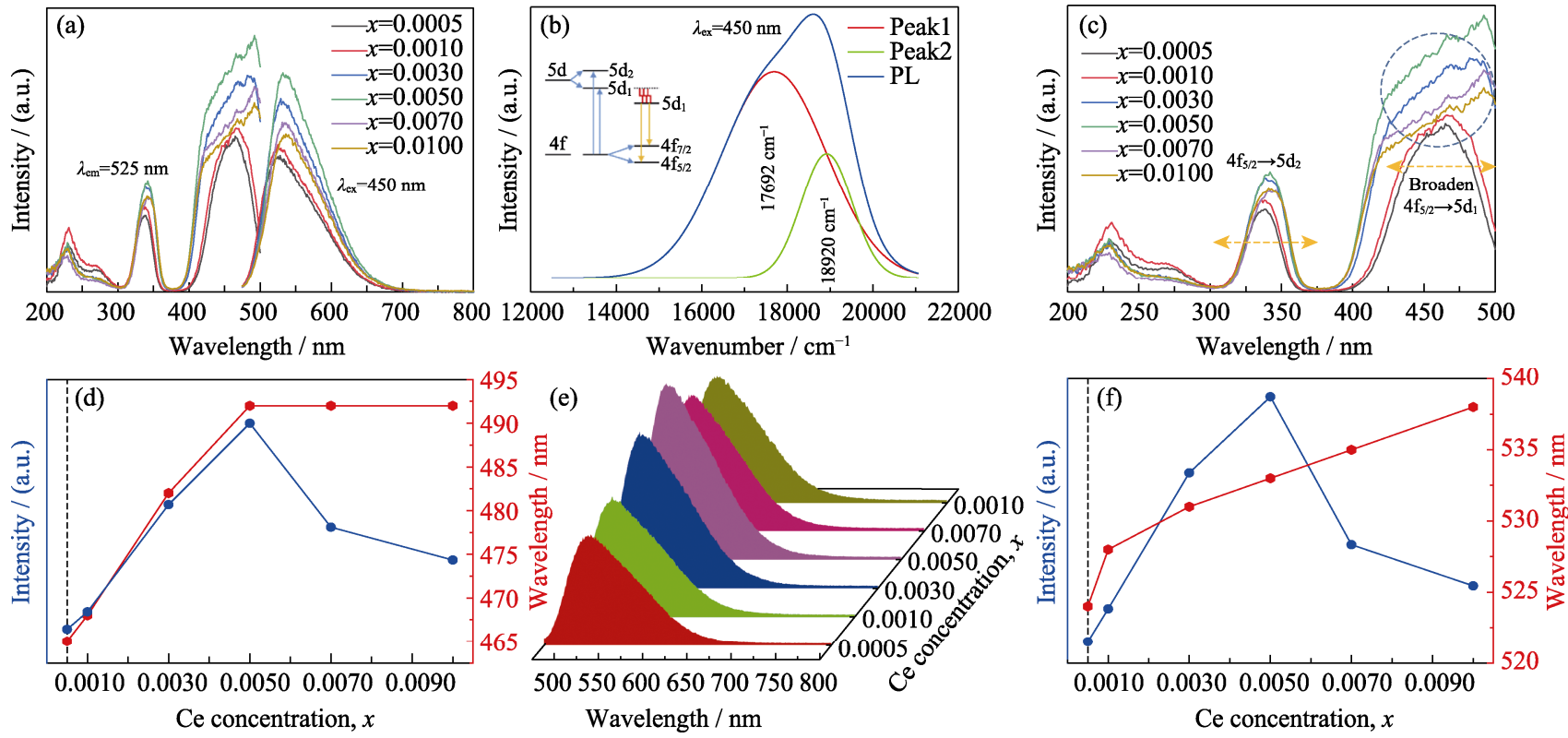

Fig. 6 PLE and PL spectra (a) of $\left(\mathrm{Ce}_{x} \mathrm{Y}_{1-x}\right)_{3} \mathrm{Al}_{5} \mathrm{O}_{12}$ ceramics, Gaussian deconvolution (b) of the 0.5 at $\%$ Ce:YAG ceramic with inset showing energy-level scheme of $\mathrm{Ce}^{3+}$, PLE $\left(\lambda_{\mathrm{em}}=525 \mathrm{~nm}\right)(\mathrm{c})$ and PL $\left(\lambda_{\mathrm{ex}}=450 \mathrm{~nm}\right)(\mathrm{e})$ of the prepared

$\mathrm{Ce}: \mathrm{YAG}$ ceramics as the function of $\mathrm{Ce}^{3+}$ doping concentration, the detailed peak positions and emission intensities of PLE (d) and PL (f) spectra of the Ce:YAG ceramics $(x=0.0005,0.0010,0.0030,0.0050,0.0070$ and 0.0100$)$

into consideration. $\mathrm{Ce}^{3+}$ doped YAG transparent ceramics can effectively absorb blue light in the range of 440 $470 \mathrm{~nm}$ and emit strong yellow emission at $530 \mathrm{~nm}$. Under blue light excitation, all samples show a broad emission band, which can be deconvoluted into two Gaussian bands peaking at $17692\left(5 \mathrm{~d}_{1} \rightarrow 4 \mathrm{f}_{7 / 2}\right)$ and $18920 \mathrm{~cm}^{-1}$ $\left(5 d_{1} \rightarrow 4 f_{5 / 2}\right)$, as shown in Fig. 6(b). As displayed in Fig. 6(c, d), the transition processes also can be understood from the illustration in the inset of Fig. 6(b). Due to the concentration quenching effect, when the content of 
$\mathrm{Ce}^{3+}$ is less than 0.0050, the luminescence intensity increases gradually with the increase of doping amount, and then decreases gradually. Through further study, it is also found that with more $\mathrm{Ce}^{3+}$ doped, the emission spectra gradually move toward the long wavelength direction. The red shift phenomenon should be due to the increase of $\mathrm{Ce}^{3+}$ concentration and the difference of radii between $\mathrm{Ce}^{3+}$ and $\mathrm{Y}^{3+}$ ions, resulting in the increase of crystal field splitting ${ }^{[30-31]}$. Meanwhile, the detailed variation trend of the emission peak positions and emission intensities of PLE and PL spectra as the function of $\mathrm{Ce}^{3+}$ concentration are provided in Fig. $6(\mathrm{~d}, \mathrm{f})$.

\subsection{Thermal analysis}

Thermal stability is an important factor to ensure the high efficiency of phosphor-converter ${ }^{[32-34]}$. Fig. 7(a) shows the temperature dependent emission spectra of $0.5 \mathrm{at} \% \mathrm{Ce}: \mathrm{YAG}$ from RT to $250{ }^{\circ} \mathrm{C}$. The decrease of emission intensity with increasing temperature can be explained by the thermal quenching in the configuration coordinate diagram of Fig. $7(d)^{[24,35]}$. The excited luminescence center is thermally activated through phonon interaction and then thermally released through the crossing point between the excited state and the ground state in the configurational coordinate diagram. This non-radial transition probability due to thermal activation is strongly dependent on temperature, resulting in a reduction in emission intensity. In addition, the peak positions of emission spectra in Fig. 7(b) exhibit a slight red shift with temperature increasing: the peak positions at RT and $250{ }^{\circ} \mathrm{C}$ are 534 and $553 \mathrm{~nm}$, respectively. The red-shift behavior can be explained by the equation for temperature dependence ${ }^{[36]}$.

$$
E_{\mathrm{T}}=E_{0}-\left(a T^{2}\right) /(T+b)
$$

where $E_{\mathrm{T}}$ is the energy difference between excited states and ground states at a temperature $T, E_{0}$ is the energy difference at $0 \mathrm{~K}$, and $a$ and $b$ are fitting parameters. At a higher temperature, the bond length between a luminescent center and its ligand ions is increased, resulting in a decreased crystal field. It results in the decrease of the transition energy, and the emission peak is red-shifted with an increase in temperature. The thermal conductivity of ceramics was calculated using $\kappa=\alpha \cdot C_{\mathrm{p}} \rho$, where $\alpha, C_{\mathrm{p}}$, $\rho$ are the heat conductivity coefficient, specific heat, and density obtained by the method described above, respectively. The relationship between the concentration of $\mathrm{Ce}^{3+}$, temperature and thermal conductivity is shown in Fig. 7(c). It can be seen that the thermal conductivity decreases with the increase of doping concentration and measuring temperature.

The temperature distribution of Ce:YAG transparent ceramics could be effectively calculated by steady-state thermal simulation using COMSOL Multiphysics finite
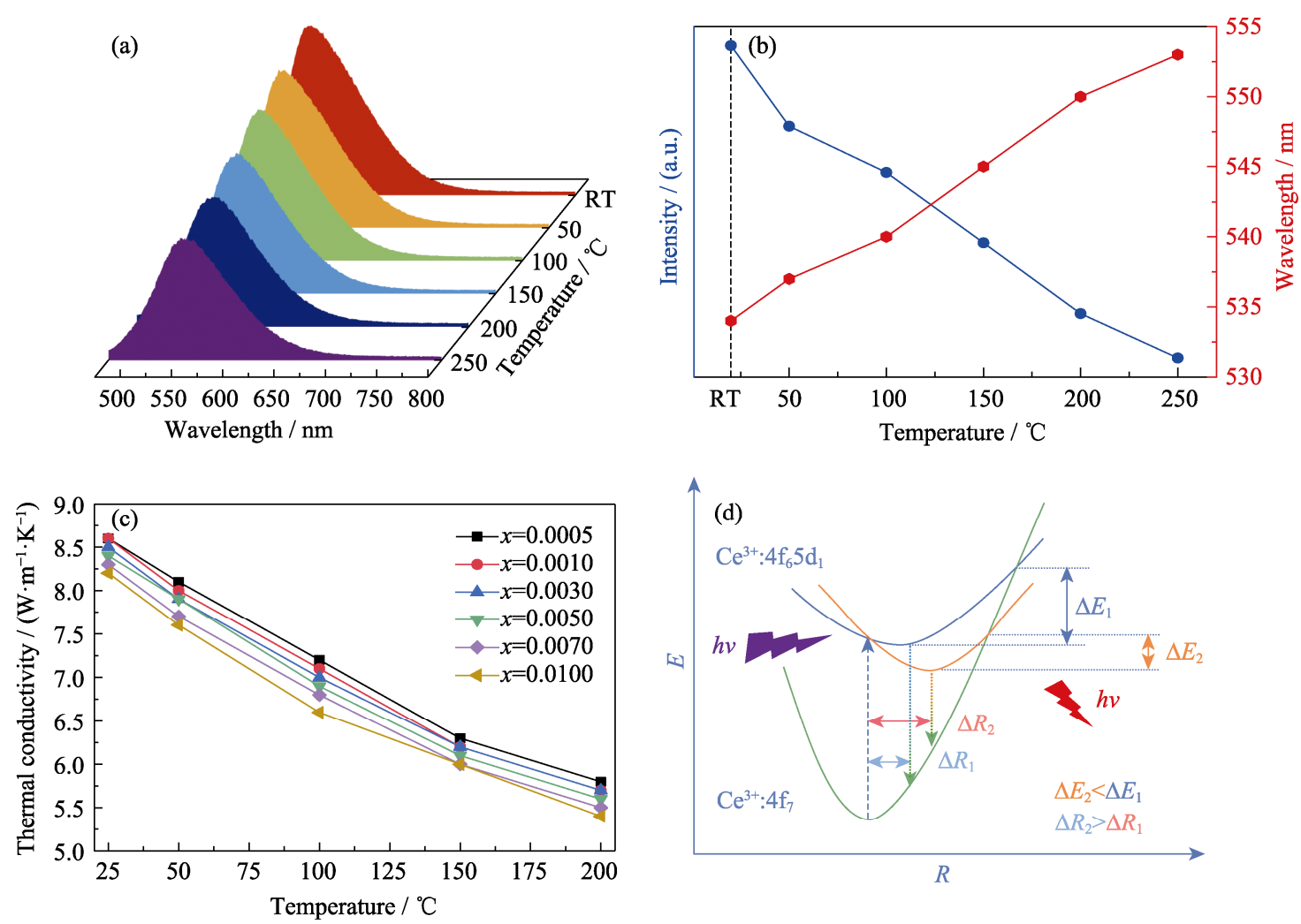

Fig. 7 Thermal quenching behavior (a) for photoluminescence $0.50 \mathrm{at} \% \mathrm{Ce}$ :YAG ceramic phosphor, detailed peak positions and emission intensities of PL spectra (b) of $0.5 \mathrm{at} \% \mathrm{Ce}$ :YAG ceramic, thermal conductivity (c) of $\left(\mathrm{Ce}_{x} \mathrm{Y}_{1-x}\right)_{3} \mathrm{Al}_{5} \mathrm{O}_{12}$ ceramics at different temperatures, and configurational coordination diagrams (d) illustrating the thermally quenching of $5 \mathrm{~d}-4 \mathrm{f}$ luminescence of $\mathrm{Ce}^{3+}$ 
element software depended upon the 3D modeling and material thermal properties. The top of Fig. 8 shows a $1: 1$ scale 3D model of COB chip and Ce:YAG transparent ceramics. In order to improve the efficiency of calculation and analysis, the tiny structure details would be ignored. Fig. 8(a, d), (b, e) and (c, f) show the thermal distributions of $0.5 \mathrm{at} \% \mathrm{Ce}: \mathrm{YAG}$ transparent ceramics with thickness of $0.2,0.4,1.0 \mathrm{~mm}$ at steady state or transient state. The thermal distribution of the three packaging modes can be drawn from the simulation results. According to the finite element simulation results, as the thickness of ceramics increases, the surface temperature of ceramics becomes lower, which is the same as the existing research and experiment results ${ }^{[19]}$. This phenomenon can be interpreted as: ceramics with the same surface area emit the same amount of heat through the surface. Thicker ceramics can emit more heat through the sides

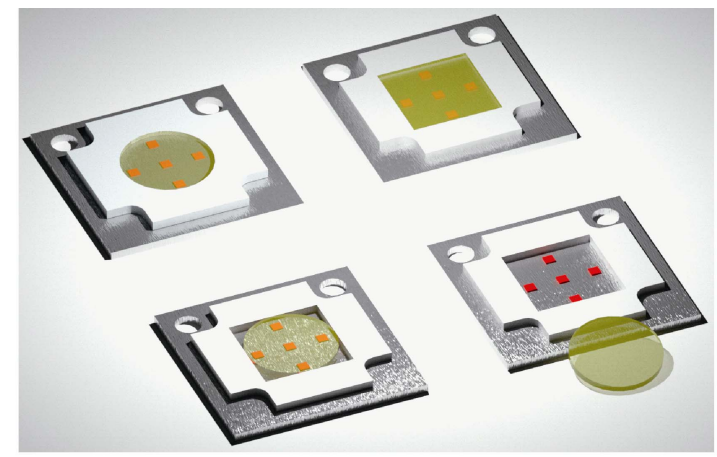

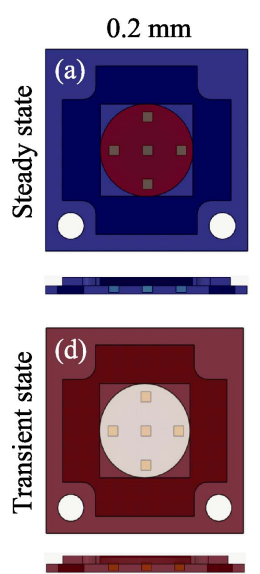

$0.2 \mathrm{~mm}$

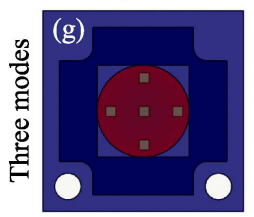

\begin{abstract}
$0.4 \mathrm{~mm}$
\end{abstract}
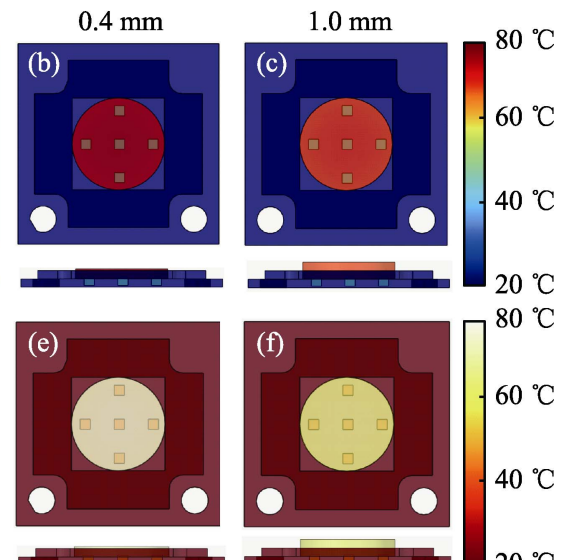

$0.2 \mathrm{~mm}$

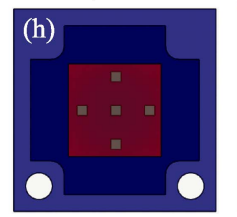

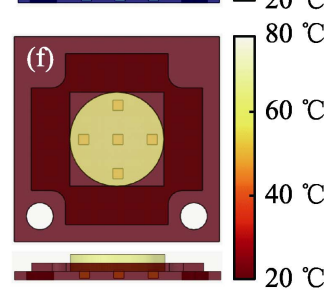

$0.2 \mathrm{~mm}$

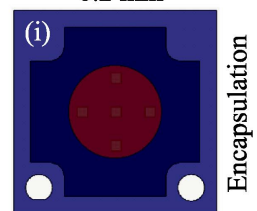

Fig. 8 Simplified three-dimensional model view of assemblage and white LEDs encapsulation model (TOP figure), thermal distribution of $0.5 \mathrm{at} \% \mathrm{Ce}: \mathrm{YAG}$ transparent ceramics, thickness $0.2 \mathrm{~mm}$ (a, d), $0.4 \mathrm{~mm}$ (b, e), $1.0 \mathrm{~mm}$ (c, f) respectively, during steady thermal state or transient thermal state, and (g-i) three common packaging methods and heat dissipation than thinner ceramics, resulting in a lower surface temperature for the thicker ceramics. Through finite element simulation, a conclusion can be drawn that thicker ceramics are conducive to heat dissipation of white LEDs devices, and increasing the thickness of the sample will reduce the composition of blue light, which will be analyzed in detail below. In addition, three common packaging methods are chosen to simulate, and find that the temperature distribution is similar, which shows that the shape of the sample has little effect on heat dissipation. The square cross-section area is obviously larger than the circular cross-section area, so the blue light in the square ceramic internal scattering process will stimulate more $\mathrm{Ce}^{3+}$ ions, which will make the composition of yellow light more, which may lead to slightly different test results of different shapes of ceramics.

\subsection{Applications for LEDs and LDs Lighting}

Fig. 9 and Fig. 10 depict the luminous characteristics of the prepared transparent ceramics under blue-emitting excitation in the LEDs/LDs lighting system. The emission spectrum of $\mathrm{Ce}^{3+}$ is wide in the range of $500-700 \mathrm{~nm}$, and the center is at $550 \mathrm{~nm}$ which is due to the electron transition of $\mathrm{Ce}^{3+}$ from $5 \mathrm{~d}$ to $4 \mathrm{f}$. In addition, the electroluminescence spectra clearly suggest that with an increase in the $\mathrm{Ce}^{3+}$ doping concentration and sample thickness, the yellow region was relatively increased because of the enhanced ceramics phosphor-conversion ratio from blue to yellow. However, the stronger phosphorconversion ability means less blue light remaining, which is not good for achieving white-light source $(0.33,0.33)$. Through a large number of tests, pure white light samples were selected, and the relevant information was recorded in Table 1. The combination of high optical quality transparent ceramics and blue LEDs and LDs not only produces pure white light, but also achieves $122.4 \mathrm{~lm} / \mathrm{W}$ and $201.5 \mathrm{~lm} / \mathrm{W}$ when the driving current is $0.01 \mathrm{~A}$ and $0.35 \mathrm{~A}$, respectively. The $\mathrm{LE}$ value is calculated by dividing the luminous flux by the electrical power. In addition, in order to prove the commercial value of transparent ceramics in the lighting industry, we combine transparent ceramics with LEDs chips to prepare a series of lamps. It can be seen from Fig. 11 that the lamp packaged by changing the concentration and thickness of transparent ceramics perfectly realized the transition from blue light to yellow light.

\section{Conclusion}

In this work, the luminescent property of Ce:YAG transparent ceramics and the device test parameters after the combination of $\mathrm{Ce}^{3+}$ concentration and transparent ceramics thickness with blue LEDs/LDs are systematically 

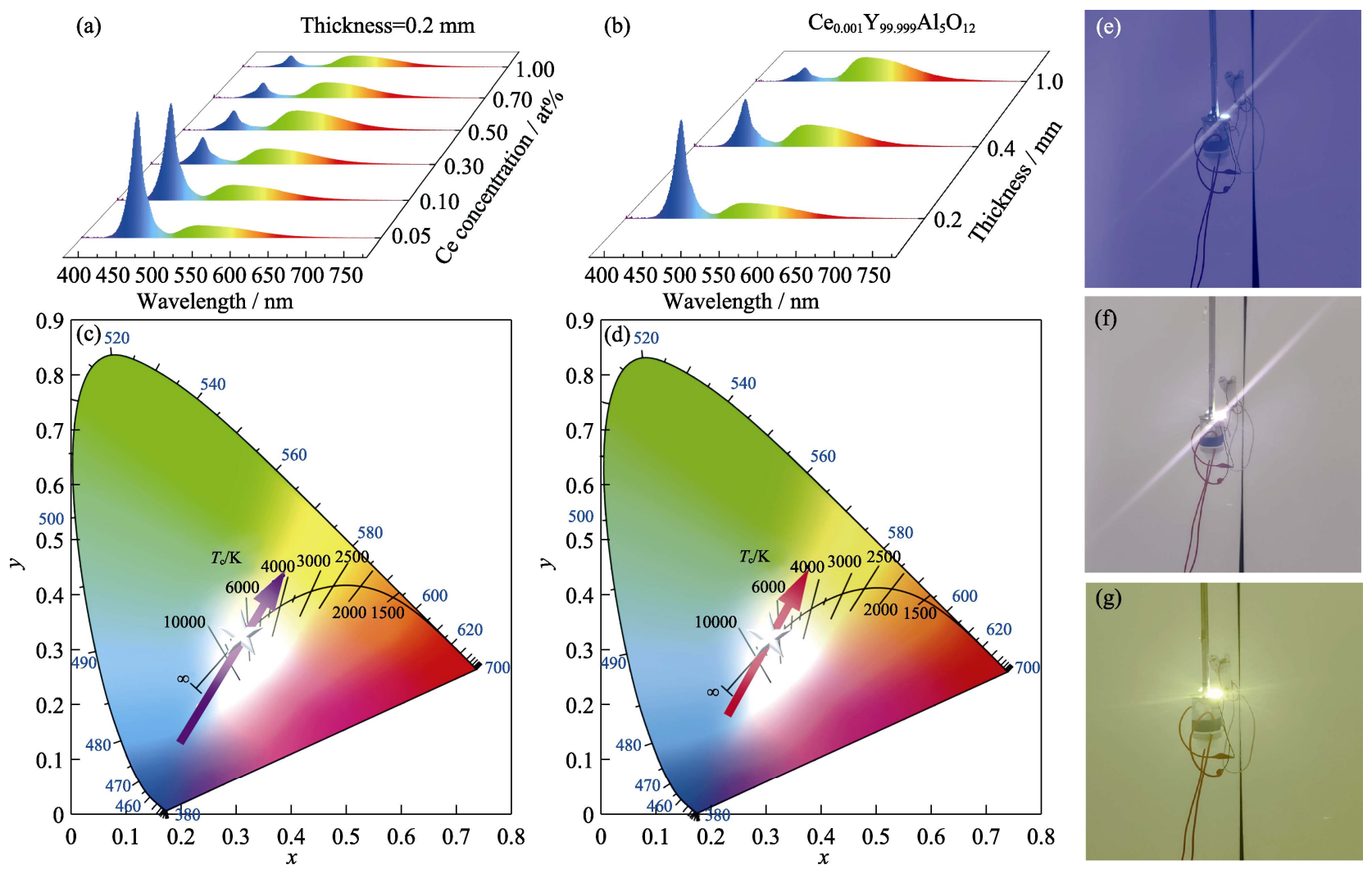

Fig. 9 EL spectra of Ce:YAG ceramics with different doping concentrations (a) and thickness (b), CIE of the LEDs with Ce:YAG ceramics of different doping concentrations (c) and thicknesses (d), the pictures of the LEDs with Ce:YAG ceramics with the increase of doping concentrations and thickness, which changes from blue to yellow (e-g)

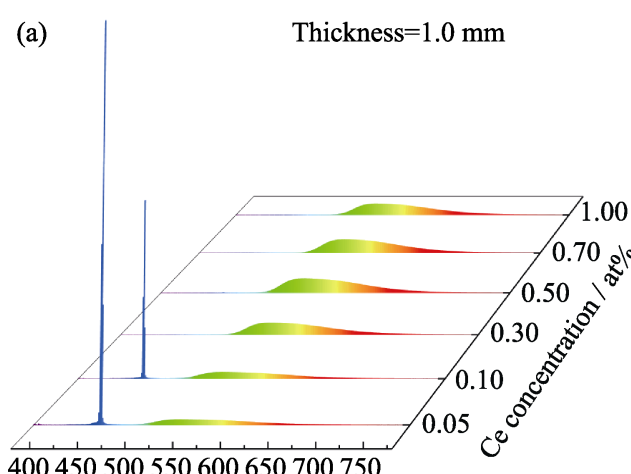

(b)

$\mathrm{Ce}_{0.005} \mathrm{Y}_{99.999} \mathrm{Al}_{5} \mathrm{O}_{12}$
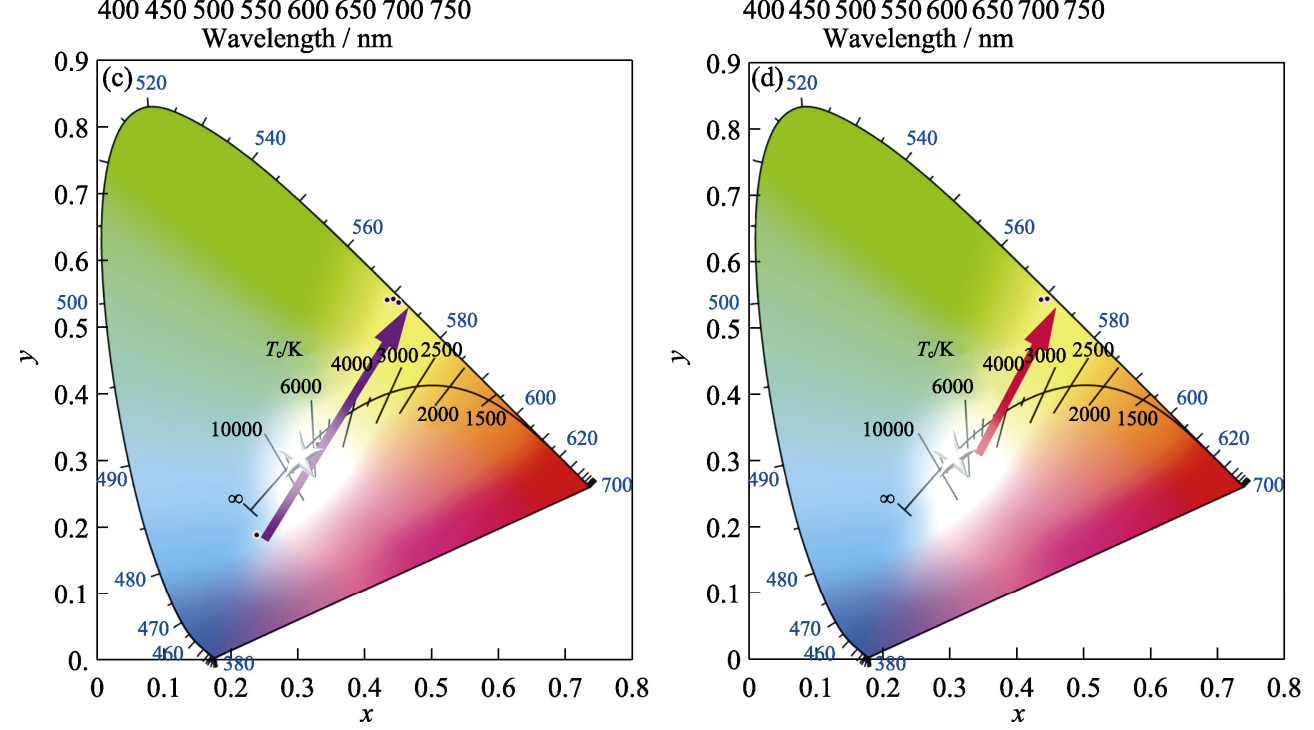

Fig. 10 EL spectra of Ce:YAG ceramics with different doping concentrations (a) and thicknesses (b), CIE of the LDs with Ce:YAG ceramics of different doping concentrations (c) and thicknesses (d) 
Table 1 White light emission parameters of Ce:YAG packaged devices $\left(\left(\mathrm{Ce}_{x} \mathrm{Y}_{1-x}\right)_{3} \mathrm{Al}_{5} \mathrm{O}_{12}\right)$

\begin{tabular}{ccccccc}
\hline LEDs/LDs & $x$ & Thickness $/ \mathrm{mm}$ & $\mathrm{LE} /\left(\mathrm{lm} \cdot \mathrm{W}^{-1}\right)$ & $\mathrm{CIE}$ & $\mathrm{CCT} / \mathrm{K}$ & $\mathrm{CRI}$ \\
\hline LED & 0.0005 & 1.0 & 122.4 & $(0.3319,0.3827)$ & 5528 & 62.8 \\
LED & 0.0010 & 0.4 & 115.5 & $(0.3021,0.3217)$ & 7196 & 68.8 \\
LED & 0.0030 & 0.2 & 83.7 & $(0.3166,0.3442)$ & 6216 & 67.1 \\
LD & 0.0010 & 1.0 & 201.5 & $(0.3298,0.3272)$ & 7415 & 65.1 \\
LD & 0.0050 & 0.2 & 170.3 & $(0.3146,0.3169)$ & 7264 & 65.4 \\
\hline
\end{tabular}

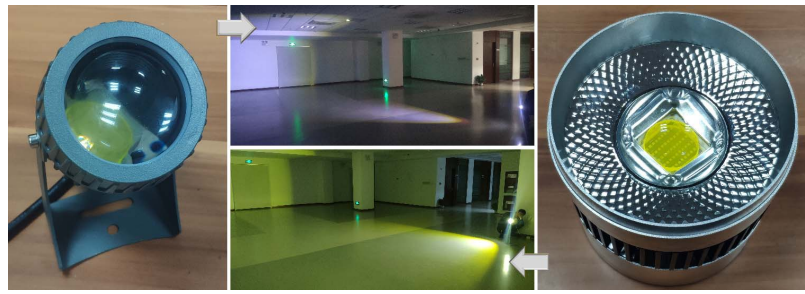

Fig. 11 Packaged LEDs devices from blue to yellow arbitrarily by adjusting the $\mathrm{Ce}^{3+}$ concentration and the thickness of transparent ceramics

studied. The great potential of Ce:YAG transparent ceramics in high-power lighting applications has proved. A series of lamps are made by combining transparent ceramics with blue LEDs chips. Only by adjusting the concentration of $\mathrm{Ce}^{3+}$ and the thickness of ceramics, the color change from white to yellow can be realized to meet the application of various scenes. In addition, this work is expected to promote the development of semiconductor lighting devices in more fields with lower energy consumption.

\section{References:}

[1] ZHENG F, MAO Y W, YANG B B, et al. Laser lighting device based on YAG:Ce ${ }^{3+}$ phosphor composite $\mathrm{Eu}^{3+}$ doped phosphor-inglasses. Chinese Journal of Luminescence, 2019, 40(7): 842-848.

[2] ZHANG J F, GU G R, DI X X, et al. Optical characteristics of $\mathrm{Ce}$,Eu:YAG single crystal grown by Czochralski method. Journal of Rare Earths, 2019, 37(2): 145-150.

[3] SHAO X C, ZHOU S M, TANG Y R, et al. Luminescence characteristics of Ce:YAG ceramic phosphors with $\mathrm{Gd}^{3+}$ doping for white light-emitting diodes. Journal of Inorganic Materials, 2018, 33(10): $1119-1123$

[4] WANG Z X, LIN H, ZHANG D W, et al. Deep-red emitting $\mathrm{Mg}_{2} \mathrm{TiO}_{4}: \mathrm{Mn}^{4+}$ phosphor ceramics for plant lighting. Journal of Advanced Ceramics, 2020, 10(1): 88-97.

[5] CHEN S L, JIANG B X, WANG Y, et al. Fabrication of Ce-doped $\left(\mathrm{Gd}_{2} \mathrm{Y}\right) \mathrm{Al}_{5} \mathrm{O}_{12} / \mathrm{Y}_{3} \mathrm{Al}_{5} \mathrm{O}_{12}$ composite-phase scintillation ceramic. Journal of Rare Earths, 2019, 37(9): 978-983.

[6] ZHENG Z H, ZHANG X, XU X K, et al. Thickness and surface roughness effect on lighting performance of $\mathrm{Ce}^{3+}: \mathrm{YAG}$ transparent ceramics based high power LED and LD lighting prototype devices. Chinese Journal of Luminescence, 2020, 41(11): 1411-1420.

[7] HUA H, FENG S W, YANG Z Y, et al. YAGG:Ce transparent ceramics with high luminous efficiency for solid-state lighting application. Journal of Advanced Ceramics, 2019, 8(3): 389-398.

[8] LIU X, ZHOU H Y, HU Z W, et al. Transparent Ce:GdYAG ceramic color converters for high-brightness white LEDs and LDs.
Optical Materials, 2019, 88(7): 97-102.

[9] CHO J, SCHUBERT E F, KIM J K, Efficiency droop in light-emitting diodes: challenges and countermeasures. Laser \& Photonics Reviews, 2013, 7(3): 408-421.

[10] BERGH A, CRAFORD G, DUGGAL A, et al. The promise and challenge of solid-state lighting. Physics Today, 2001, 54(12): 42-47.

[11] CAO Y F, HAN T, YANG J Y, et al. Tunable-spectrum $\mathrm{Mn}^{2+}$ doped garnet transparent ceramics for high-color rendering laser lighting. International Journal of Applied Ceramic Technology, 2021, 18: 716-723.

[12] LI S X, WANG L, HIROSAKI N, et al. Color conversion materials for high-brightness laser-driven solid-state lighting. Laser \& Photonics Reviews, 2018, 12(12): 1800173-1800203.

[13] PAN G H, WU H J, HE S, et al. Dye-embedded YAG:Ce ${ }^{3+} @ \mathrm{SiO}_{2}$ composite phosphors toward warm wLEDs through radiative energy transfer: preparation, characterization and luminescence properties. Nanoscale, 2018, 10(47): 22237-22251.

[14] SONG Y H, JI E K, JEONG B W, et al. High power laser-driven ceramic phosphor plate for outstanding efficient white light conversion in application of automotive lighting. Scientific Reports, 2016, 6(1): 31206-31213.

[15] LIN Z B, LIN H, XU J, et al. Highly thermal-stable warm w-LED based on Ce:YAG PiG stacked with a red phosphor layer. Journal of Alloys and Compounds, 2015, 649(1): 661-665.

[16] WANG L, WEI R, ZHENG P, et al. Realizing high-brightness and ultra-wide-color-gamut laser-driven back lighting by using laminated phosphor-in-glass (PiG) films. Journal of Materials Chemistry C, 2020, 8(5): 1746-1754.

[17] YAO Q, ZHANG L, ZHANG J, et al. Simple mass-preparation and enhanced thermal performance of Ce:YAG transparent ceramics for high power white LEDs. Ceramics International, 2019, 45(5): 6356-6362.

[18] WAETZIG K, KUNZER M and KINSKI I, Influence of sample thickness and concentration of Ce dopant on the optical properties of YAG:Ce ceramic phosphors for white LEDs. Journal of Materials Research, 2014, 29(19): 2318-2324.

[19] LIU G H, ZHOU Z Z, SHI Y, et al. Ce:YAG transparent ceramics for applications of high power LEDs: thickness effects and high temperature performance. Materials Letters, 2015, 139(1): 480-482.

[20] SHANG M M, FAN J, LIAN H Z, et al. A double substitution of $\mathrm{Mg}^{2+}-\mathrm{Si}^{4+} / \mathrm{Ge}^{4+}$ for $\mathrm{Al}_{(1)}{ }^{(3+)}-\mathrm{Al}_{(2)}{ }^{3+}$ in $\mathrm{Ce}^{3+}$-doped garnet phosphor for white LEDs. Inorganic Chemistry, 2014, 53(14): 7748-7755.

[21] AO G, TANG Y R, YI X Z, et al. Red emission generation in $\mathrm{Ce}^{3+} / \mathrm{Mn}^{2+}$ co-doping $\mathrm{Y}_{3} \mathrm{Al}_{5} \mathrm{O}_{12}$ phosphor ceramics for warm white lighting emitting diodes. Journal of Alloys and Compounds, 2019, 798(17): 695-699.

[22] KANG J, ZHANG L, LI Y B, et al. Luminescence declining behaviors in YAG:Ce transparent ceramics for high power laser lighting. Journal of Materials Chemistry C, 2019, 7(45): 14357-14365.

[23] XIA Z G, MEIJERINK A. Ce ${ }^{3+}$-doped garnet phosphors: composition modification, luminescence properties and applications. Chemical Society Reviews, 2017, 46(1): 275-299. 
[24] LIU S, SUN P, LIU Y F, et al. Warm white light with a high color-rendering index from a Single $\mathrm{Gd}_{3} \mathrm{Al}_{4} \mathrm{GaO}_{12}: \mathrm{Ce}^{3+}$ transparent ceramic for high-power LEDs and LDs. ACS Applied Materials \& Interfaces, 2018, 11(2): 2130-2139.

[25] TOLMACHEV R P, TOLMACHEV A V, Thermostimulated luminescence from single crystals of modified lithium gadolinium orthoborate $\mathrm{Li}_{6-x} \mathrm{Na}_{x} \mathrm{Gd}\left(\mathrm{BO}_{3}\right)_{3}:$ Ce. Technical Physics Letters, 2004, 30(12): 8-14.

[26] ZHANG W, LU T C, WEI N, et al. Effect of annealing on the optical properties of Nd:YAG transparent ceramics. Optical Materials, 2012, 34(4): 685-690.

[27] ZHANG W, LU T, MA B Y, et al. Improvement of optical properties of Nd:YAG transparent ceramics by post-annealing and post hot isostatic pressing. Optical Materials, 2013, 35(12): 2405-2410.

[28] STEVENSON A J, BITTEL B C, LEH C G, et al. Color center formation in vacuum sintered $\mathrm{Nd}_{3 x} \mathrm{Y}_{3-3 x} \mathrm{Al}_{5} \mathrm{O}_{12}$ transparent ceramics. Applied Physics Letters, 2011, 98(5): 051906-051909.

[29] SONG Z, LIU X L, HE L Z, et al. Correlation between the energy level structure of cerium-doped yttrium aluminum garnet and luminescent behavior at varying temperatures. Materials Research Express, 2016, 3(5): 055501-055509.

[30] SUN P, HU P, LIU Y F, et al. Broadband emissions from $\mathrm{Lu}_{2} \mathrm{Mg}_{2} \mathrm{Al}_{2} \mathrm{Si}_{2} \mathrm{O}_{12}: \mathrm{Ce}^{3+}$ plate ceramic phosphors enable a high color- rendering index for laser-driven lighting. Journal of Materials Chemistry C, 2020, 8(4): 1405-1412.

[31] PAN Z F, CHEN J C, WU H Q, et al. Red emission enhancement in $\mathrm{Ce}^{3+} / \mathrm{Mn}^{2+}$ co-doping suited garnet host $\mathrm{MgY}_{2} \mathrm{Al}_{4} \mathrm{SiO}_{12}$ for tunable warm white LED. Optical Materials, 2017, 72(5): 257-264.

[32] YEH C W, CHEN W T, LIU R S, et al. Origin of thermal degradation of $\mathrm{Sr}_{2-x} \mathrm{Si}_{5} \mathrm{~N}_{8}$ :Eu $\mathrm{Eu}_{x}$ phosphors in air for light-emitting diodes. Journal of the American Chemical Society, 2012, 134(34): 14108-14117.

[33] ZHANG L L, ZHANG S, HAO Z D, et al. A high efficiency broad-band near-infrared $\mathrm{Ca}_{2} \mathrm{LuZr}_{2} \mathrm{Al}_{3} \mathrm{O}_{12}: \mathrm{Cr}^{3+}$ garnet phosphor for blue LED chips. Journal of Materials Chemistry C, 2018, 6(18): 4967-4976.

[34] GU C, WANG X J, XIA C, et al. A new $\mathrm{CaF}_{2}$-YAG:Ce composite phosphor ceramic for high-power and high-color-rendering WLEDs. Journal of Materials Chemistry C, 2019, 7(28): 8569-8574.

[35] KIM J S, PARK Y H, KIM S M, et al. Temperature-dependent emission spectra of $\mathrm{M}_{2} \mathrm{SiO}_{4}: \mathrm{Eu}^{2+}(\mathrm{M}=\mathrm{Ca}, \mathrm{Sr}, \mathrm{Ba})$ phosphors for green and greenish white LEDs. Solid State Communications, 2005, 133(7): 445-448.

[36] WANG Y H, DING J Y, WANG Y C, et al. Structural design of new $\mathrm{Ce}^{3+} / \mathrm{Eu}^{2+}$-doped or co-doped phosphors with excellent thermal stabilities for WLEDs. Journal of Materials Chemistry C, 2019, 7(7): 1792-1820.

\title{
高光效、大功率 LEDs/LDs 用 Ce:YAG 透明陶瓷
}

\author{
杜傲宸 $^{1,2}$, 杜琪源 ${ }^{3}$, 刘 欣 ${ }^{2,4}$, 杨益民 ${ }^{1,2}$, 夏晨阳 ${ }^{1}$, 邹 军 $^{3}$, 李 江 $^{2,4}$
}

(1. 吉林建筑大学 材料科学与工程学院, 长春 130118; 2. 中国科学院 上海硅酸盐研究所, 透明光功能无机材料重 点实验室, 上海 201899; 3. 上海应用技术大学 理学院, 上海 201418; 4. 中国科学院大学 材料与光电研究中心, 北 京 100049)

摘 要: Ce:YAG 透明陶瓷可与蓝光 $L E D s / L D s$ 复合, 用于大功率白光 $L E D s / L D s$ 。本研究通过调整 Ce:YAG 透明陶 瓷的厚度和 $\mathrm{Ce}^{3+}$ 的掺杂浓度, 将组装器件的发射光谱和色坐标从冷白区调整到暖白区。以高纯 $(\geqslant 99.99 \%)$ 商业粉体 $\alpha-\mathrm{Al}_{2} \mathrm{O}_{3} 、 \mathrm{Y}_{2} \mathrm{O}_{3} 、 \mathrm{CeO}_{2}$ 为原料, 采用固相反应法制备了 $\left(\mathrm{Ce}_{x} \mathrm{Y}_{1-x}\right)_{3} \mathrm{Al}_{5} \mathrm{O}_{12}(x=0.0005 、 0.0010 、 0.0030 、 0.0050 、 0.0070$ 和 0.0100 )透明陶瓷。陶瓷素坏在 $1750{ }^{\circ} \mathrm{C}$ 真空烧结 $20 \mathrm{~h}$ (真空度 $5.0 \times 10^{-5} \mathrm{~Pa}$ ), 之后在马弗炉中退火 $1450{ }^{\circ} \mathrm{C} \times 10 \mathrm{~h}$ 。 不同掺杂浓度 $\mathrm{Ce}: \mathrm{YAG}$ 陶瓷(厚度分别为 $0.2 、 0.4 、 1.0 \mathrm{~mm}$ ) 在 $800 \mathrm{~nm}$ 处的直线透过率均大于 $79 \%$ 。 $\mathrm{e}: \mathrm{YAG}$ 苂光 陶瓷的热导率随着测试温度和掺杂浓度的增加而降低。采用有限元方法模拟不同厚度的 Ce:YAG 陶瓷和 LED 组装 的热分布, 比较了三种封装方式的热分布。将 Ce:YAG 荧光陶瓷与 LEDs/LDs 复合, 制备出色坐标分别为 $(0.3319$, $0.3827)$ 和 $(0.3298,0.3272)$ 的白光, 发光效率分别为 122.4 和 $201.5 \mathrm{~lm} / \mathrm{W}$ 。将 Ce:YAG 苂光陶瓷和 $10 、 50 \mathrm{~W}$ 商用蓝 光 LED 芯片组合成熟灯具, 可用于商业用途。Ce:YAG 透明陶瓷在大功率照明和显示的彩色转换材料应用领域极 具潜力。

关 键 词: LEDs/LDs 照明; 光致发光; Ce:YAG; 苂光陶瓷

中图分类号: TQ174 文献标志码: A 